\title{
A Comparative Study of Phosphonate and Phosphorus-Free Antiscalant Efficiency by Static and Dynamic Methods. Do We Have Reliable Tools For An Adequate Reagent Selection?
}

\author{
Popov $\mathrm{K}^{1 *}$, Boglovskiy $\mathrm{A}^{2}$, Gorbunov $\mathrm{A}^{2}$, Guseva $\mathbf{0}^{1}$, Larchenko $\mathrm{V}^{1}$, and Rudakova $\mathrm{G}^{1}$ \\ ${ }^{1}$ PJSC, Fine Chemicals R\&D Centre, Russia
}

${ }^{2}$ National Research University, Moscow Power Engineering Institute, Russia

Submission: April 17, 2017; Published: April 28, 2017

*Corresponding author: Konstantin Popov, PJSC, Fine Chemicals R\&D Centre, Krasnobogatyrskaya ul, 42, str1,Moscow, 107258, Russia , Email: ki-popov@mtu-net.ru

\begin{abstract}
A relative ability of four industrial samples of phosphorus-free polymers (polyaspartate, PASP; polyepoxysuccinate, PESA; polyacrylic acid sodium salt, PAAS; copolymer of maleic and acrylic acid, MA-AA) and of two phosphonates (aminotris(methylenephosphonic acid), ATMP; 1-hydroxyethane-1,1-bis(phosphonic acid), HEDP) to inhibit calcium carbonate precipitation at a dosage $10 \mathrm{mg}^{\bullet} \mathrm{dm}^{-3}$ is tested in static experiments following the NACE Standard TM0374-2007 and in a dynamic modeofevaporation plant for Caspian Sea water imitate. The reagent efficiency ranking following NACE Standard gives evidently a preference to phosphonates over polymers: ATMP HEDP $>$ PESA (400-1,500 Da) $\sim$ PASP (1,000-5,000 Da)>PAAS (3,000-5,000 Da) MA-AA. At the same time the kinetic tests exhibit the better efficiency of PESA and MA-AA: $\mathrm{PESA}>\mathrm{MA}-\mathrm{AA}>\mathrm{PAAS} \sim \mathrm{HEDP}>\mathrm{ATMP} \sim \mathrm{PASP}$. Therefore, a lot of work is still needed to elaborate a system of laboratory tests for antiscalants in order to provide reliable assessment and selection on their way from laboratory to industry.
\end{abstract}

Keywords: Scale inhibition; Calcium carbonate; Polymers; Phosphonates; NACE

\section{Introduction}

Scale formation in the oil and gas industry, evaporation plants, reverse osmosis desalination processes, steam generators, boilers, cooling water towers and pipes is a serious problem, causing significant plugging of wells, pipe-lines, membranes, and increasing the production expenses [1,2]. A widely used technique for controlling scale deposition is an application of chemical inhibitors [1-4]. Commonly used commercial antiscalants are represented by organophosphonates and numerous modifications of polyacrylates (PA). Among these the organophosphonates are dominating recently at the World market [5]. At the same time phosphorus-based inhibitors are hardly biodegradable and persist for many years after their disposal, which leads to eutrofication problems. Phosphorus discharges are therefore regulated in many countries worldwide, and permissible limits are constantly decreasing.

Increasing environmental concerns and discharge limitations have forced the scale-inhibitor chemistry to move toward "green antiscalants" that are readily biodegradable and have minimal environmental impact. Intensive efforts are applied recently to develop the "green" alternatives to organophosphonates and nonbiodegradable polyacrylates [1-4]. Among these novel inhibitors, such chemicals as polymaleates (MA), polyaspartates (PASP), polyepoxysuccinates (PESA), as well as their various derivatives, including co-polymers with PA are the most promising. It is important to note, that the new antiscalants should have acceptable levels of performance at a cost-effective dose rate. This requirement raises a problem of reliable tests, which permit a correct "old red" and "novel green" inhibitors efficiency comparison [6]. Indeed, most of the data published on $\mathrm{CaCO}_{3}\left(\mathrm{CaSO}_{4}\right)$ deposition are studied under hardly comparable conditions, e.g., different $\mathrm{CaCO}_{3}$ supersaturationindex, brine composition, temperature, $\mathrm{pH}$, measurement technique, etc. This leads to the quite opposite opinions on the relative Antiscalant's efficacy, reported by different research groups for one and the same set of reagents proposed for one and the same scale (see $[1,7,8]$ and references there). 
Table 1: impact of $10 \mathrm{mg} \cdot \mathrm{dm}^{-3}$ inhibitor dosages on $\mathrm{CaCO}_{3}$ scaling according to kinetic and static testament $A$ full scale paper is in preparation paper is now underway: [8].

\begin{tabular}{|c|c|c|c|}
\hline \multirow{2}{*}{ Regent } & \multicolumn{2}{|c|}{ Caspian Sea water imitate* } & \multirow{2}{*}{$\begin{array}{c}\text { I, \% } \\
\text { (NACE } \\
\text { brine)** }\end{array}$} \\
\cline { 2 - 3 } & $\boldsymbol{\tau}_{\text {ind }}$, min & $\boldsymbol{\tau}_{\mathbf{1} / \mathbf{2}}$, min & 0 \\
\hline Blank & $<5$ & $\sim 5$ & 93 \\
\hline PESA & 60 & $>240$ & 89 \\
\hline PASP & 30 & 90 & 83 \\
\hline PAAS & 20 & 140 & 88 \\
\hline MA-AA & 60 & 230 & 100 \\
\hline HEDP & 15 & 130 & 100 \\
\hline ATMP & 15 & 90 & \\
\hline
\end{tabular}

Specific Technology Group (STG) 31 on Oil and Gas Production-Corrosion and Scale Inhibition has elaborated a procedure of static laboratory antiscalants screeningNACE Standard TM0374-2007 [9]. These test methods are recommended only for ranking the performance of different scale inhibitors under laboratory conditions set by these methods. They are not intended to provide actual field treating rates. Surely, the scale inhibitor concentration required for a field application is likely to be different from that determined under these laboratory conditions. However, it is assumed, that for a particular set of reagents the ranking would be the same, and an inhibitor evaluation prior to final scale inhibitor selection is valid for the field use as well. Although particularly the NACE Standard is not very common, a lot of researchers use recently very similar approaches $[1,7,8]$.

Present paper is therefore focused on the assessment of relative antiscalants efficacy against $\mathrm{CaCO}_{3}$ scale formation predicted following NACE protocol, and their ranking found by kinetic experiments run under conditions close to those used at evaporation plants.

\section{Materials and Methods}

Polymer based industrialantiscalants, polyasparticacid sodium salt (PASP, 1000-5000 Da), copolymer of maleic and acrylic acid (MA-AA), polyepoxysuccinic acid (PESA, 400-1500 Da), and sodium salt of polyacrylic acid (PAAS, 3000-5000 Da), have been kindly supplied by Shandong Taihe Water Treatment Technologies Co., Ltd., while industrial solid posphonates aminotris (methylenephosphonic acid), ATMP and 1-hydroxyethane-1,1-bis (phosphonic acid), HEDP have been supplied by a manufacturer OAO "Khimprom," Novocheboksarsk, Russia.

Kinetic tests have been run operating with a model evaporation plant bench-scale facility. A freshly prepared imitate of the Caspian Sea water $\left(\left[\mathrm{Ca}^{2+}\right] 0.35 \mathrm{~g} \bullet \mathrm{dm}^{-3}, 0.0088\right.$ $\mathrm{mol} \bullet \mathrm{dm}^{-3} ;\left[\mathrm{HCO}_{3}-\right]$ g• $\mathrm{dm}^{-3}, 0.15 \mathrm{~mol} \bullet \mathrm{dm}^{-3}$; pH 8.5-9.8) was kept boiling at $85{ }^{\circ} \mathrm{C}$ under reduced pressure $(59 \mathrm{kPa})$ for a period of 240 minutes. A reflux condenser provided the total liquid phase volume constancy. Periodically the boiling brine was sampled and analyzed for $\left[\mathrm{Ca}^{2+}\right]$ content by EDTA titration procedure. Then the induction precipitation time $\left(\tau_{\text {ind }}, \min \right)$ and a half deposition time $\left(\tau_{1 / 2}\right)$ have been calculated. Here $\tau_{1 / 2}$ is denoted as a moment, when $\left(C-C_{f}\right) /\left(C_{0}-C_{f}\right)=0,5$; where $C$ - current calcium concentration; $\mathrm{C}_{\mathrm{f}}$ - final calcium concentration found from a blank experiment, $\mathrm{C}_{0}$ - initial calcium concentration. All experiments were run in duplicates. The difference between duplicate run results was less than $10 \%$.

Following the NACE Standard TM0374-2007 [9] two synthetic brines was prepared with distilled water: calciumcontaining brine $\left(12.15 \mathrm{~g} \bullet \mathrm{dm}^{-3} \mathrm{CaCl}_{2} \cdot 2 \mathrm{H}_{2} \mathrm{O} ; 3.68 \mathrm{~g} \bullet \mathrm{dm}^{-3}\right.$ $\left.\mathrm{MgCl}_{2} \cdot 6 \mathrm{H}_{2} \mathrm{O} ; 33.0 \mathrm{~g} \bullet \mathrm{dm}^{-3} \mathrm{NaCl}\right)$ and bicarbonate-containing brine (7.36 g• $\mathrm{dm}^{-3} \mathrm{NaHCO}_{3} ; 33.0 \mathrm{~g} \bullet \mathrm{dm}^{-3} \mathrm{NaCl}$ ) saturated by $\mathrm{CO}_{2}$. Being mixed at $1: 1$ volume ratio, these brines give a supersaturated calcium carbonate solution: $6.07 \mathrm{~g} \bullet \mathrm{dm}^{-3}(6,070$ ppm) $\mathrm{CaCl}_{2} \cdot 2 \mathrm{H}_{2} \mathrm{O}, 1.84 \mathrm{~g} \bullet \mathrm{dm}^{-3}(1,840 \mathrm{ppm}) \mathrm{MgCl}_{2} \bullet 6 \mathrm{H}_{2} \mathrm{O}, 3.68$ $\mathrm{g} \bullet \mathrm{dm}^{-3}(3,680 \mathrm{ppm}) \mathrm{NaHCO}_{3}$ and $33.0 \mathrm{~g} \bullet \mathrm{dm}^{-3}(33,000 \mathrm{ppm}) \mathrm{NaCl}$. The ionic strength of this solution provided mostly by $\mathrm{NaCl}$ by the end of the precipitation process wasaround $0.71 \mathrm{~mol} \bullet \mathrm{dm}^{-3}$. Supersaturated solution of calcium carbonate with a calculated amount of inhibitor $\left(10 \mathrm{~g} \bullet \mathrm{dm}^{-3}\right)$ was then kept for $24 \mathrm{~h}$ at $71^{\circ} \mathrm{C}$, cooled and analyzed for residual calcium content by EDTA titration. The $\mathrm{pH}$ of the solutions at $25^{\circ} \mathrm{C}$ was about 7. All experiments were run in duplicates. The difference between duplicate run results was less than $5 \%$.The performance of the tested compounds as calcium carbonate antiscalants was calculated as inhibition percentage (I, \%):

$\mathrm{I}, \%=100 \times\left([\mathrm{Ca}]_{\exp }-[\mathrm{Ca}]_{\text {final }}\right) /\left([\mathrm{Ca}]_{\text {init }}-[\mathrm{Ca}]_{\text {final }}\right)$. Where: $[\mathrm{Ca}]$ exp : concentration of calcium in the filtrate in the presence of an inhibitor at 24 hours; $[\mathrm{Ca}]_{\text {final }}$ : concentration of calcium in the filtrate in the absence of an inhibitor at 24 hours; $[\mathrm{Ca}]_{\text {init }}$ : concentration of calcium at the beginning of the experiment. All experimental results are presented in a Table.

\section{Results and Discussion}

The reagent efficiency ranking following NACE Standard gives evidently a preference to phosphonates over polymers: ATMP $\sim$ HEDP $>$ PESA $(400-1,500$ Da $) \sim$ PASP $(1,000-5,000$ Da $)$ $>$ PAAS $(3,000-5,000 \mathrm{Da}) \sim \mathrm{MA}-\mathrm{AA}$. Thus, among the studied set of reagents ATMP and HEDP should be expected to become a matter of choice for carbonate scaling. However, an attempt to implement these reagents to evaporation plants gives a sufficiently different ranking. According to $\tau_{\text {ind }}$ : PESA MAAA $>$ PASP $>$ PAAS $>$ HEDP $\sim$ ATMP

The $\tau_{1 / 2}$ datareveals in turn another sequence: PESA $>$ MAAA $>$ PAAS $\sim$ HEDP $>$ ATMP PASP. 
In any case PESA and MA-AA look more preferable than phosphonates for evaporation plants. Actually $\tau_{1 / 2}$ seems to be a more adequate indicator than $\tau_{\text {ind }}$. The latter characterizes only the initial nucleation step, while the former is responsible for both: initial nucleation and further crystal growth kinetics. Anyhow the data given above demonstrates clearly that a lot of work is still needed to elaborate a system of laboratory tests for antiscalants in order to provide reliable assessment and selection on their way from laboratory to industry.

\section{Conclusion}

A comparison of static and dynamic laboratory testaments of scale inhibitors indicates for one and the same set of reagents rather conflicting results. Static test gives preference to the phosphonates ATMP and HEDP, while the dynamic one to polymers PESA and MA-AA. Thus a lot of work is still needed to elaborate some conventional methods for the reliable, particular case-focused reagent efficiency prediction.

\section{Acknowledgements}

The authors would like to thank the Russian Foundation for Basic Research (Project No. 17-08-00061) and partly the Ministry of Education and Science of the Russian Federation.

\section{Conflict of Interest}

For a present study no any economic interest or any conflict of interest exists.

\section{References}

1. Hasson D, Shemer H, Sher A (2011) State of the art of friendly "green" scale inhibitors: a review article. Ind Eng Chem Res 50(12): 7601-7607.
2. Popov KI, Kovaleva NE, Rudakova GY, Kombarova SP, Larchenko VE, et al. (2016) Recent state-of-the-art of biodegradable scale inhibitors for cooling-water treatment applications (review). Therm Eng 63(2): 122129.

3. Shemer H, Hasson D (2015) Characterization of the inhibitory effectiveness of environmentally friendly anti-scalants. Desalinationand Water Treatment, 55(13): 3478-3484.

4. Amjad Z, Landgraf TR, Penn JL (2015) Calcium sulfate dihydrate (gypsum) scale inhibition by PAA, PAPEMP, and PAA/PAPEMP blend. Int. J. Corros. Scale Inhi 3(1): 35-47.

5. (2019) Scale Inhibitor Market by Type and by Application-GlobalTrends \& Forecast http://www.researchandmarkets.com/reports/2933881/ scale-inhibitor-market-by-type-and-byapplication\#\%20pos-0.

6. Shemer H, Hasson D, Semiat R (2012) Review of the state of the art of antiscalant selection, Abstracts of Papers, 244th ACS National Meeting \& Exposition, Philadelphia, PA, United States, August 19-23, COLL-165.

7. Popov K, Rudakova G, Larchenko V, Tusheva M, Kamagurov S, et al (2016) Comparative Performance Evaluation of Some Novel «Green» and Traditional Antiscalants in Calcium Sulfate Scaling. Advances in Materials Science and Engineering 2016, 7635329 p. 10.

8. Popov K, Rudakova G, Larchenko V, Tusheva M, Afanas'eva E, et al. (2017) A comparative performance ranking of some phosphonates and environmentally friendly polymers on $\mathrm{CaCO}_{3}$ scaling inhibition by NACE protocol Desalination and Water Treatment 69: 163-172.

9. (2007) NACE Standard TM0374-2007 (formerly TM0374-2001), Item No. 21208, Laboratory Screening Tests to Determine the Ability of Scale Inhibitors to Prevent the Precipitation of Calcium Sulfate and Calcium Carbonate from Solution (for Oil and Gas Production Systems).
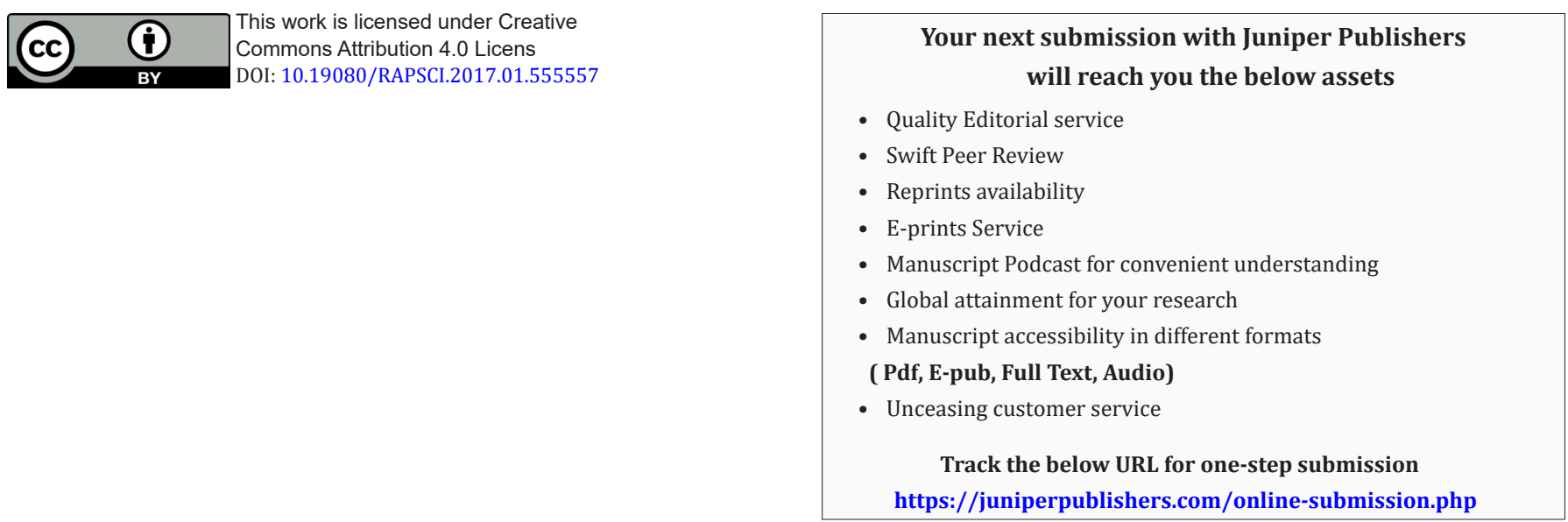